\title{
Is Long-Term Prognosis for Pervasive Developmental Disorder Not Otherwise Specified Different from Prognosis for Autistic Disorder? Findings from a 30-Year Follow-Up Study
}

\author{
Marianne Mordre • Berit Groholt • Ann Kristin Knudsen • \\ Eili Sponheim • Arnstein Mykletun • \\ Anne Margrethe Myhre
}

Published online: 29 June 2011

(c) The Author(s) 2011. This article is published with open access at Springerlink.com

\begin{abstract}
We followed 74 children with autistic disorder (AD) and 39 children with pervasive developmental disorder not otherwise specified (PDD NOS) for 17-38 years in a record linkage study. Rates of disability pension award, marital status, criminality and mortality were compared between groups. Disability pension award was the only outcome measure that differed significantly between the AD and PDD NOS groups (89\% vs. $72 \%$, $p<0.05)$. The lower rate of disability pension award in the PDD NOS group was predicted by better psychosocial functioning. The lack of substantial differences in prognosis between the groups supports a dimensional description of autism spectrum disorder, in line with proposed DSM-V revision.
\end{abstract}

Keywords Autistic disorder - PDD NOS - CGAS . Adult outcome

M. Mordre $(\varangle)$ · E. Sponheim · A. M. Myhre

Division of Mental Health and Addiction, Oslo University

Hospital, P.O. Box 4956, Nydalen, 0424 Oslo, Norway

e-mail: marianne.mordre@medisin.uio.no

B. Groholt · A. M. Myhre

Institute for Clinical Medicine, University of Oslo,

Oslo, Norway

A. K. Knudsen · A. Mykletun

Department of Health Promotion and Development,

Faculty of Psychology, University of Bergen, Bergen, Norway

A. Mykletun

Department of Mental Health,

Norwegian Institute of Public Health, Oslo, Norway

\section{Introduction}

Pervasive developmental disorder not otherwise specified (PDD NOS) is a subthreshold diagnosis within autism spectrum disorder (ASD) that does not fulfill the full set of criteria for autistic disorder (AD). AD is a strictly defined category with pervasive problems in terms of communication, social relatedness, and stereotyped or repetitive behaviors (American Psychiatric Association 2000). PDD NOS is used as a residual category for individuals with a broader autism phenotype. During the last decade, several studies have questioned the adequacy of the current PDD NOS category (Allen et al. 2001; Buitelaar et al. 1999; Volkmar et al. 2009; Walker et al. 2004). In some studies, children with PDD NOS have been found to have less restrictive and repetitive behaviors than children with autism, but the literature so far has been unable to clearly differentiate children with PDD NOS from children with AD (Allen et al. 2001; Buitelaar et al. 1999; Walker et al. 2004). Distinctions have been reported to be inconsistent and associated with language level and cognitive ability rather than with autistic symptoms (American Psychiatric Association 2010).

In the new revision of DSM (DSM-V), PDD NOS together with AD, Asperger's disorder, and childhood disintegrative disorder have been suggested to be subsumed under a single diagnostic category, described dimensionally, because of inconsistencies between ASD subgroups (American Psychiatric Association 2010).

Predictive validity can be an important aspect of the clinical utility of a diagnostic category (First et al. 2004; Volkmar et al. 2009). If individuals with PDD NOS have the same prognosis and outcome as individuals with $\mathrm{AD}$, this would support the assumption of an artificial diagnostic distinction. Knowledge of the prognosis and 
outcome for individuals with PDD NOS is however, scarce, whereas, the outcome for $\mathrm{AD}$ is well known. In both clinical (Cederlund et al. 2007; Howlin et al. 2000, 2004; Larsen and Mouridsen 1997) and population-based studies (Billstedt et al. 2005; Gillberg and Steffenburg 1987; von Knorring and Hagglof 1993), about two-thirds of the individuals diagnosed with $\mathrm{AD}$ fare poorly in employment, education, independent living and peer relations.

Only one study has described adult outcome for individuals with PDD NOS defined according to the current DSM-IV criteria (Hofvander et al. 2009). In this study, Hofvander et al. reported poor psychosocial outcome for 50 individuals with PDD NOS, five individuals with AD, and 67 individuals with Asperger's disorder, all of whom were outpatients with normal intelligence. Only $40 \%$ were employed and $84 \%$ had never lived in a long-term relationship at follow-up (median age 29 years). However, outcome comparisons between ASD subgroups were not reported. In a previous study, Billstedt et al. (2005) studied 78 individuals with $\mathrm{AD}$ and 42 individuals with autisticlike conditions (according to DSM-III-R) in a populationbased follow-up study (mean age 25.5 years at follow-up). They found that, regardless of subgroups, $78 \%$ of the participants had a poor overall outcome with an obvious severe handicap. However, because only $18 \%$ of the population had intellectual levels above 70 , the results could not be extrapolated to individuals with intellectual levels in the upper range. In an early population-based study of 46 children suffering from either infantile autism or other childhood psychoses (OP), Gillberg and Steffenburg (1987) reported that $59 \%$ had a poor outcome in early adulthood, with a tendency toward better outcome in the infantile autism group. Interpretation of the results in this study is, however, difficult because of the heterogeneity of the OP group and their associated handicaps.

The aim of the present study was to compare adult outcome of individuals with PDD NOS and individuals with AD, diagnosed according to DSM-IV. We wanted to explore whether vulnerability factors other than ASD subdiagnoses enhanced the prediction of outcome.

\section{Methods}

\section{Study Population}

The study population consisted of 113 inpatients with ASD. They were all part of a larger study population consisting of all consecutively admitted inpatients ( $n=550$ ) to the children's unit at the National Centre for Child and Adolescent Psychiatry in Oslo (NCCAP), Norway, from the opening of the children's unit in January 1968-October 1988. Specialized child psychiatric services were not available all over Norway during this period, especially not in sparsely populated areas. Children with long-lasting, complex or rare disorders were referred to the hospital from all over the country for assessment and inpatient treatment when local outpatient clinics were short of professional expertise. Many children were admitted as inpatients for practical reasons, because NCCAP was located far from their homes. The children's unit at NCCAP provided specialized treatment for children up to 13 years of age. The institution did not have an emergency unit and none of these children were in acute crisis when they were hospitalized.

The hospital records for each individual provided baseline information and detailed descriptions of symptoms, psychological test results, school performance and extensive anamnestic information about the children and their families.

The gender distribution in the ASD group studied was $23(20 \%)$ girls and $90(80 \%)$ boys. The mean age at admission was 7.1 years (SD 2. 6, range 3-13 years), with no gender differences. Fifty-six $(50 \%)$ of the patients were admitted to the family ward, $53(47 \%)$ to the inpatient long-term ward, and four $(3 \%)$ to the day care ward. The mean length of stay was 1.3 months (SD 1.6) in the family ward, 12.7 months (SD 18.6) in the inpatient long-term ward, and 35.5 months (SD 17.6) at the day care ward. Thirty-three percent of the patients were admitted more than once. The mean age at follow-up (excluding those who had emigrated or died) was 36.6 years (SD 7.1, range 22-48 years) and the mean follow-up period was 29.5 years (SD 6.5, range 17-38 years). By follow-up, three $(3 \%)$ individuals in the study population had died and three $(3 \%)$ had emigrated.

\section{Outcome Variables}

The participants were identified by personal identification number in the population register at the Central Bureau of Statistics at follow-up in December 2005. Rates of mortality and criminality were obtained from the Cause of Death Registry and the Criminal Records Registry. Information on marital status and disability pension award was obtained from Statistics Norway's events database FD-Trygd (which includes demographic details and information from the Norwegian Labour and Welfare Organisation) at follow-up in December 2005. All citizens of Norway are eligible after 18 years of age (age 16 until January 1st 1998) to be granted a disability pension award for an acknowledged medical condition that causes more than $50 \%$ lasting reduction in work capacity. The right to a disability pension award is not means tested and no prior work participation is required. It is solely a public responsibility, and, as in most northern European countries, 
it is a fairly generous welfare scheme compared with those in many other countries.

The Norwegian Labour and Welfare Organisation records information on all disability pension awards. Correct registration is a prerequisite for transfers of payments and the records are thus highly accurate. Findings reported in the Criminal Records Register were based on court convictions for infractions of all breaches of the law. All the registers were complete, valid and up to date.

Measures

\section{Diagnostic Classification (DSM-IV)}

Based on chart review, the 550 inpatients were rediagnosed according to the current DSM-IV criteria, independent of diagnosis at admission. The children admitted represented a broad variety of child psychiatric disorders. Of the 550 inpatients, 113 children fulfilled the DSM-IV criteria for either AD, Asperger's disorder (AS) or PDD NOS. They constituted the group studied in this paper.

Using hospital records, the patients were rediagnosed by the first author and independently by at least one other experienced child psychiatrist. If two raters disagreed, consensus diagnoses were set by a research group of four child psychiatrists (including one expert in the field of autism).

\section{Sociodemographic Variables}

Gender and age were registered at baseline. We also applied a global assessment of Chronic Family Difficulties (CFD) based on all the information available in the hospital records concerning the patients' past and present family situations (Vandvik et al. 1989). Socioeconomic conditions, social network, marital or family discord and current/ previous physical and mental health of the family members were recorded. The total burden of difficulties was scored on an interval scale from 0 to 6 . A score of 0 reflects no sign of chronic family difficulties and a score of 6 reflects severe difficulties/very disturbed family environment.

\section{Intellectual Level}

An assessment of each participant's intellectual level was based on all the information available in the hospital records, including clinical findings, psychometric test results (in some cases standardized intelligence tests, such as the Wechsler Intelligence Scale for Children (WISC), the Standford-Binet Intelligence Scales, or the Leiter International Performance Scale) and pedagogic tests (such as the Illinois Test of Psycholinguistic Abilities (ITPA) and the Peabody Picture Vocabulary Test) administered during hospitalization. Teachers at NCCAP's affiliated school performed systematic pedagogic evaluations for school-age children.

Diagnostic criteria for level of mental retardation were used according to DSM-IV. Because previous research has shown that having an IQ of at least 70 is a crucial prognostic factor (Howlin et al. 2004), intellectual level was dichotomized in terms of mental retardation (MR) yes/no which correspond to the approximate cut-off for IQ scores that were either greater or less than 70 . In three cases (3\%), there was not enough information in the records to assess intellectual level and thus the corresponding data were recorded as missing.

\section{Organic Brain Dysfunction}

Organic brain dysfunction was registered if neuroanatomical pathology was documented in the medical record (e.g., diagnoses of cerebral palsy, hemiparesis or organic brain dysfunction given by neurologists) or if there was focal epileptogen activity on the EEG.

\section{Children's Global Assessment Scale (CGAS)}

Based on chart review, the children's CGAS scores were assigned by the raters. The CGAS is a widely used clinician rated scale assigning a single summary score to describe psychosocial functioning (Bird et al. 1996; Shaffer et al. 1983). The instrument is validated against many different psychiatric assessment scales (Winters et al. 2005), and validity is good at distinguishing cases from no cases (Bird et al. 1987, 1990). The scale runs from 1 to 100 , with 1 indicating the most severely disordered child and 100 the best-functioning child. The assessment was based on the child's functioning at the time of admission, as described in the hospital records. Because no children were admitted to the hospital due to an acute crisis situation, the ratings reflect the child's long-term problems.

\section{Interrater Study}

An interrater reliability study was carried out for 476 individuals in the initial study population, yielding an overall kappa value of 0.77 for Axis 1 diagnoses and a kappa of 0.89 for differentiating ASD from non-ASD patients (ASD subtyping was based on consensus). For 96 of the 113 ASD individuals, the CGAS intraclass correlation coefficient (ICC) was 0.62 . In five cases, the discrepancy between raters was more than 12 points. When these cases were excluded, the interrater reliability was considered satisfactory with an ICC of 0.73 . The interrater reliability was very good for CFD with ICC of 0.82 and ICC of 0.88 for intellectual level. 
Statistical Methods

Descriptive statistics are presented as means with standard deviations, medians and ranges, as appropriate. Variables were examined using Student's two-sample $t$ test for continuous variables, and Pearson's chi-square test and Fisher's exact test for categorical variables. Binary logistic regression analyses were used to analyze the risk of disability pension awards. The youngest age for registration of disability pension awards in Norway was 16 years of age during the study period (age 18 since January 1st 1998). Those individuals who died or emigrated before the age of 16 ( $n=3$ ) were excluded from the estimates of disability, marital status and conviction rates, as well as from the binary logistic regression analyses. The effects of possible prognostic variables for disability pension award were tested using univariate binary logistic regression analysis. CGAS and CFD were continuous variables, whereas, intellectual function and comorbid brain dysfunction were dichotomized. Variables with $p<0.250$ in the univariate analyses were included in a multivariate logistic regression analysis. The least significant factors were excluded one by one until the remaining factor(s) were significant at the $p=0.05$ level. Results are presented as odds ratios (OR) with corresponding 95\% confidence intervals (CI). The Hosmer and Lemeshow goodness of fit test was used to evaluate final models. The study group was compared with the average Norwegian population in 2005, using Table statistics (StatBank Norway 2005).

SPSS version 15 was used for the statistical analyses.

\section{Ethics}

The study was approved by the Regional Committee of Ethics in Medical Research, the Department of Health and Social Services, and the Norwegian Data Inspectorate.

\section{Results}

\section{ASD Subgroups}

AD was diagnosed in $74(65 \%)$ children according to DSM-IV, of whom $11(10 \%)$ children who met the criteria for AS were included.

PDD NOS was diagnosed in 39 individuals (35\%) who either did not fully meet the DSM-IV criteria for AD or whose symptom onset occurred after 3 years of age. Characteristics of the AD and PDD NOS groups are given in Table 1.
General Adult Outcome in AD and PDD NOS Groups

Rates of disability pension award, marital status, convictions and mortality in AD and PDD NOS groups are shown in Table 2.

Disability Pension Award

At follow-up, 91 persons (83\%) in the ASD group had received a disability pension award. There was a significantly higher rate of disability in the AD group compared with the PDD NOS group (89\% vs. $72 \%, p<0.05$; Table 2), but the disability rate in both groups was markedly increased relative to the same age groups in the general population, where a crude estimate was $5 \%$ (The Norwegian Labour and Welfare Administration 2005). The mean age when the disability pension was awarded was 17.1 years (SD 3.9, range 16-40 years), with no significant difference between the AD and PDD NOS groups. By 22 years of age, 87 of $91(96 \%)$ individuals had been awarded a disability pension. Of the four registered later, two were in the AD group and two in the PDD NOS group.

\section{Marital Status}

Almost all in the ASD population were unmarried at follow-up, with no difference between AD and PDD NOS groups (99\% vs. $92 \%$, ns; Table 2), compared with about $50 \%$ in the general population (StatBank Norway 2005).

\section{Convictions}

Two (3\%) individuals with AD and five (13\%) individuals with PDD NOS had been convicted at follow-up $(p=0.10$; Table 2$)$. The overall crime rate $(n=7.6 \%)$ in the ASD group was a little more than half of the occurrence in the general population (10\%) (Kjelsberg and Dahl 1998; Skardhamar 2010). The offenders were all men, and they had been convicted for different kinds of offences e.g., interpersonal aggression and threats, crimes against property, and drug violations.

\section{Mortality}

One male with $\mathrm{AD}(2 \%)$ and one male $(3 \%)$ with PDD NOS had died by the time of follow-up $(p>0.05)$, compared with $2 \%$ in the general male population, adjusted for age (http://www.ssb.no). Among 23 ASD females, one AD female $(4 \%)$ had died by follow-up, compared with $1 \%$ in the general female population, adjusted for age (StatBank Norway 2005). 
Table 1 Characteristics of AD and PDD NOS groups at admission

\begin{tabular}{lccc}
\hline & AD $=74$ & PDD NOS $=39$ & $p$ value \\
\hline Male gender & $59(80 \%)$ & $31(80 \%)$ & 0.27 \\
Age at admission $^{\mathrm{a}}$ & $6.7($ SD 2.6) & 7.7 (SD 2.3) & $\mathbf{0 . 0 4}$ \\
MR $^{\mathrm{a}, \mathrm{b}}$ & $51(71 \%)$ & $23(61 \%)$ & 0.27 \\
Organic brain disorder $^{\mathrm{a}}$ & $11(15 \%)$ & $5(13 \%)$ & 0.78 \\
CFD $^{\mathrm{a}}$ & $3.0($ SD 1.4) & 3.5 (SD 1.3) & 0.08 \\
CGAS $^{\mathrm{a}}$ & 31 (SD 6.2) & 33 (SD 5.7) & $\mathbf{0 . 0 3}$ \\
\hline
\end{tabular}

Significant differences are given in bold

$M R$ mental retardation, $C F D$ chronic family difficulties, CGAS children's global assessment scale

${ }^{\text {a }}$ No gender differences

b Two missing cases in the AD group and one missing case in the PDD NOS group

Table 2 Rates of disability pension award, marital status, criminality and mortality in AD group and PDD NOS group at follow-up in 2005 with $95 \%$ confidence interval $(\mathrm{CI})$

\begin{tabular}{llll}
\hline Outcome & $\mathrm{AD}(n=74)$ & PDD NOS $(n=39)$ & $p$ value \\
\hline Disability pension award $^{\mathrm{a}}$ & $63(89 \%, \mathrm{CI}=81-96)$ & $28(72 \%, \mathrm{CI}=58-86)$ & $\mathbf{0 . 0 3}$ \\
Marital status- unmarried $^{\mathrm{a}, \mathrm{b}}$ & $70(99 \%, \mathrm{CI}=96-100)$ & $35(92 \%, \mathrm{CI}=84-100)$ & 0.19 \\
Criminality $^{\mathrm{a}}$ & $2(3 \%, \mathrm{CI}=0-7)$ & $5(13 \%, \mathrm{CI}=2-23)$ & 0.10 \\
Mortality & $2(3 \%, \mathrm{CI}=0-7)$ & $1(3 \%, 0)$ & 1.00 \\
\hline
\end{tabular}

Significant differences are given in bold

a Those individuals who emigrated or died before the age of $16(n=3$ with $\mathrm{AD}$ ) were excluded from the analyses

${ }^{\mathrm{b}}$ One missing case in the PDD NOS group

Predictors of Disability Pension Award

Disability pension award was the only outcome measure in this study that was significantly different between the AD and PDD NOS groups (Table 2). Using binary logistic regression analyses, we examined the associations between subsequent disability pension award and AD and PDD NOS, and variables we wanted to adjust for: gender, MR, CFD, organic brain disorder and CGAS, in 110 individuals, none of whom died or emigrated before the age of 16 (Table 3).

The results of the univariate binary logistic regression analyses showed that four variables (PDD NOS, CGAS, MR and CFD) had significance levels below 0.250, and they were all entered into a multivariate logistic regression. Only one variable remained significant in the final model: CGAS (OR 0.8, 95\% CI $=0.7-0.9, p<0.001)$. Because CGAS and level of intellectual functioning represented overlapping constructs (Pearson's correlation 0.54, $p<0.001$ ), separate analyses were performed without CGAS. Main vulnerability factor for disability pension then was MR (data not shown). Because we chose to include those with AS $(n=11)$ in the AD group, we also ran separate logistic analyses with the AS group excluded. CGAS still remained the only significant factor in the final model $(p<0.001$, data not shown).

\section{Discussion}

In the present study, we found small differences in adult outcome between individuals with $\mathrm{AD}$ and individuals with PDD NOS. The overall adult outcome in both AD and PDD NOS groups was poor, with excessively increased disability rates in both groups relative to the general population, and with almost all individuals being unmarried at follow-up. There were no elevated mortality or conviction rates in either group. Disability pension award was the only outcome measure that differed between the diagnostic subgroups, and that was explained by difference in psychosocial functioning (CGAS) rather than by diagnostic category.

\section{Disability Pension Award and Marital Status}

Eighty-three percent of the individuals in this study received disability pension awards, and $95 \%$ were unmarried at follow-up. This is consistent with previous studies showing poor prognosis in ASD individuals (Billstedt et al. 2005; Gillberg and Steffenburg 1987; Cederlund et al. 2007; Hofvander et al. 2009; Howlin et al. 2000, 2004; von Knorring and Hagglof 1993). In our study, 35\% of the ASD individuals were diagnosed with PDD NOS. Despite a lower symptom load in this group, we found a markedly 
Table 3 Prevalence of vulnerability factors and OR estimates by univariate logistic regression of the study population of those who received $(N=91)$ and those who did not receive $(N=19)$ disability pension award (DP) at

Significant relative risks are given in bold

$M R$ mental retardation, $C F D$ chronic family difficulties, $C G A S$ children's global assessment scale

a Those individuals who emigrated or died before the age of 16 ( $n=3$ with $\mathrm{AD}$ ) were excluded from the analyses

b Three missing cases follow-up in 2005

\begin{tabular}{llllll}
\hline Vulnerability factors & $N=110^{\mathrm{a}}$ & $\mathrm{DP}(N=91)$ & No DP $(N=19)$ & OR $(95 \% \mathrm{CI})$ & $p$ value \\
& & $N(\%)$ or mean & $N(\%)$ or mean & & \\
& $(\mathrm{SD})$ & $(\mathrm{SD})$ & & \\
\hline
\end{tabular}

Mental health(DSM-IV)

$N=71$

$63(89 \%)$

$8(11 \%)$

1.0

PDD NOS

$N=39$

$28(72 \%)$

$11(28 \%)$

$0.3(0.1-0.9)$

0.029

Socio demographic variables

\begin{tabular}{|c|c|c|c|c|c|}
\hline $\begin{array}{l}\text { Female gender } \\
\text { (reference) }\end{array}$ & $N=22$ & $19(86 \%)$ & $3(14 \%)$ & 1.0 & \\
\hline Male gender & $N=88$ & $72(82 \%)$ & $16(18 \%)$ & $0.7(0.2-2.7)$ & 0.615 \\
\hline CFD & $N=110$ & $3.1(\mathrm{SD} 1.4)$ & $3.6(\mathrm{SD} 1.2)$ & $0.8(0.5-1.1)$ & 0.178 \\
\hline \multicolumn{6}{|c|}{$\mathrm{MR}^{\mathrm{b}} / \mathrm{brain}$ dysfunction/CGAS } \\
\hline No MR (reference) & $N=36$ & $25(69 \%)$ & $11(31 \%)$ & 1.0 & \\
\hline MR & $N=71$ & $64(90 \%)$ & $7(10 \%)$ & $4.0(1.4-11.5)$ & 0.010 \\
\hline $\begin{array}{l}\text { No organic brain } \\
\text { dysfunction } \\
\text { (reference) }\end{array}$ & $N=95$ & $77(81 \%)$ & $18(19 \%)$ & 1.0 & \\
\hline $\begin{array}{c}\text { Organic brain } \\
\text { dysfunction }\end{array}$ & $N=15$ & $14(93 \%)$ & $1(7 \%)$ & $3.3(0.4-26.5)$ & 0.267 \\
\hline CGAS & $N=110$ & $30(\mathrm{SD} 5)$ & 38 (SD 6) & $0.8(0.7-0.9)$ & $<\mathbf{0 . 0 0 1}$ \\
\hline
\end{tabular}

elevated rate of disability pension awards, and a substantial majority was unmarried also in this group. Our findings are in line with two previous studies that reported similar severe handicaps in adults with PDD NOS/autistic-like conditions, in which few individuals were living normal social lives and functioning well at work (Billstedt et al. 2005; Hofvander et al. 2009). Hofvander et al. reported a somewhat better prognosis for their participants than for ours or Billstedt's, but this is probably attributable to the normal-range intellectual level of their individuals. In our study, $33 \%$ of the patients were in the upper intellectual range compared with only $18 \%$ in the Billstedt study, but the prognosis was similar, with a poor outcome in almost $80 \%$ of the cases in both studies. However, comparisons must only be tentative. In our study, outcome was based on marital status, disability pension award, mortality and convictions as measures for prognosis. Billstedt et al. used the more graded outcome criteria published by Lotter (Lotter 1974).

\section{Predictors of Disability Pension Award}

Childhood intellectual level and language function before age 6 years have been reported to be the most important predictors of outcome in ASD individuals (Baghdadli et al. 2007; Billstedt et al. 2005; Howlin et al. 2004; Kobayashi et al. 1992; Szatmari et al. 2003). In the present study, disability pension award was the outcome measure providing most information about adult outcome. Interestingly, our results indicated that low psychosocial function (CGAS) at admission seemed to be more associated with disability pension award at follow-up than intellectual level. These factors are obviously interacting, but the results suggest that assessment of CGAS, in addition to intellectual level, provide useful information about outcome. Because CGAS is a global measure, it also measures adaptive capacity, which is one of the most impaired functions in individuals with ASD. Thus, this instrument may capture important information relevant to prognosis ASD populations known to be difficult to test and where precise IQ scores may be unreliable, assessing CGAS may be especially useful. However, few previous studies have used CGAS as a predictor of outcome (DeMaso et al. 1995; Gold et al. 1993; Sourander et al. 1996), and less research has been conducted on the measurement of functional impairment than on psychiatric disorders (Szatmari 2009). Szatmari and colleagues (Szatmari et al. 2002) have claimed that the severity of symptoms and level of functioning are two phenotypic dimensions that do not always correlate. CGAS incorporates both these dimensions in one global assessment and could therefore be useful as an additional tool when estimating outcome in individuals with ASD.

We found that $\mathrm{AD}$ was no more associated with disability pension award than was PDD NOS when we adjusted for intellectual level and CGAS. This is in line with research conducted by Billstedt et al. (2005), in which $\mathrm{AD}$ and other ASD subgroups with similar intellectual levels were equally predictive of a poor outcome. Because our findings indicate that outcome seem to depend more on level of functioning than degree of autistic symptoms, our that intellectual level as a prognostic factor may miss. In 
findings support a dimensional model of ASD as proposed in the DSM-V revision (American Psychiatric Association 2010).

Previous research has paid little attention to whether contextual variables predict later outcome in ASD individuals (Seltzer et al. 2004). We found no association between chronic family difficulties and subsequent disability pension at follow-up, nor did we find any gender differences. This is consistent with Howlin's findings (1997), who reported that the effects of family factors and gender were unclear. However, mapping contextual factors that promote or impede development in ASD individuals should be emphasized in future research. The prevalence of ASD has increased markedly within the last decades (Fombonne 2005), and many people will need the support of their families and society in the future. With regard to gender, reported studies have often suffered from small female samples (Billstedt et al. 2005; Gillberg and Steffenburg 1987; Howlin 1997; Piven et al. 1996), and future research must use larger female populations to draw conclusions about gender differences.

\section{Convictions}

Only seven individuals in our ASD population were convicted of crimes. The low conviction rate is in line with the results of Mouridsen et al. (2007), who found that former child psychiatric inpatients with ASD had about half the conviction rate of a matched control group. However, five out of seven convicted patients in our sample belonged to the PDD NOS group, and recent studies have found that there are differences in criminal behavior between subgroups of people with ASD (Mouridsen et al. 2007; Siponmaa et al. 2001). The tentative, but not statistically significant, difference we found in our study may have been caused by the different intellectual and functional levels between the groups, but a definitive answer awaits future research on larger populations.

\section{Mortality}

The mortality rate among males $(2 \%)$ in our study must be regarded with caution because of the small numbers, but it did not seem to be high in either the AD group or the PDD NOS group. Previous research has found that persons with ASD tend to have an increased mortality risk (Gillberg et al. 2010; Mouridsen et al. 2008; Shavelle et al. 2001), regardless of ASD subtypes (Gillberg et al. 2010). However, research on mortality in ASD populations is limited, and the representativeness of study populations has been unclear. In our study, only $14 \%$ of the individuals had a comorbid organic brain disorder at baseline, which contrasts with a study by Gillberg et al. (2010) in which a large proportion of the participants had additional specific medical disorders.

With one female (4\%) from a small female population registered dead at follow-up, we cannot conclude anything about female mortality, but our findings do not contradict recent research in which female gender were associated with an increased risk of early death (Mouridsen et al. 2008; Shavelle et al. 2001).

\section{Strengths and Limitations}

The present study has several strengths. We have examined a large group of patients. It is a nation-wide study, and no regional admission bias should be in force. The follow-up period is long relative to that used in most other studies. Rediagnosis and scoring of the study population was completed before the outcome information was collected, and thus scoring was performed blind to outcome. The reliance on four experienced clinicians (one expert in the field of autism) to make consensus best-estimate diagnoses ensured that the diagnosis of PDD NOS was applied as accurately as possible. The outcomes are based on highquality national registers.

The present study also has some general limitations that must be considered when interpreting the results. Followup studies of clinical samples will always have problems with representativeness of such samples. This study is based on inpatient admissions only, and the study population may not be representative of child psychiatric patients in general. However, the NCCAP was a national institution and patients were referred from all over Norway. During the period we examined, fewer children were seen at local clinics and individuals with suspected pervasive developmental disorders were often admitted as inpatients. These factors make our population less selective than would have been the case today. Because our ASD population was identified by chart review, according to current DSM-IV criteria, and not upon the criteria at the time of admission, we also ensured that children representing the broader spectrum of autism disorders than strictly defined AD were included.

All information was based on chart review from hospital records, which are not reliable scientific sources of information in all aspects. File-based information should always be interpreted with caution. However, the hospital records were of good quality, giving a detailed and thorough description of the patients' symptoms and behavior, psychometric test results and family functioning. All the records were read independently by at least two clinicians, and the rediagnosis and scoring of the data were completed by experienced psychiatrists. We conducted an extensive interrater reliability study, and the interrater reliability was high for the diagnoses. This is consistent with previous 
research in which validity of file-based diagnostic ratings has been satisfactory (Grann et al. 1998; McKenzie et al. 2011).

Unfortunately, standardized IQ instruments were not systematically used during hospitalization. To mitigate this problem, we reassessed the cognitive level according to DSM-IV criteria for level of mental retardation. The interrater reliability for the cognitive level assessments was very good, reflecting the detailed information about cognitive attainment in the records.

We also found the CGAS and CFD scale scores to be reasonably reliable between raters, in line with previous research (Aasland et al. 1997; Bird et al. 1987; Flato et al. 1997). The detailed medical histories in the hospital records largely compensated for the lack of direct observations of the children and their families.

The outcome measures were derived from register data, and prognosis was based on disability pension award, marital status, convictions and mortality. We did not use the Lotter (1974) outcome criteria ("good", "fair", "restricted" and "poor") that are most often used in other studies, so comparisons must be done with caution and prognoses should only be tentative. The outcome measures we used, however, were robust official register data, and they were not influenced by the investigators.

Factors identified in this study are probably not causative factors, but rather they are markers of vulnerability factors that increase the risk of disability pension award within an ASD population, and they should be interpreted as such.

Finally, if the proposed DSM-V criteria are accepted, this study compares outcome differences in diagnostic groups that would no longer exist. However, we believe our study still adds information about the long-term outcome of ASD individuals, while supporting the future dimensional approach.

\section{Conclusions}

In summary, the results of this study of a large group of ASD individuals that we followed into adulthood suggest that the overall outcome is poor regardless of ASD subgroups. The results did not indicate substantial differences between individuals with autistic disorder and those with pervasive developmental disorders not otherwise specified. Prognosis was associated with psychosocial function and intellectual level rather than ASD subcategories, and thus our findings support a dimensional description of ASD individuals that is in line with proposed DSM-V revision. Our findings also indicate that a simultaneous consideration of symptom severity and functional impairment, implemented in the Children Global Assessment Scale (CGAS), could enhance the prediction of outcome.

Acknowledgments We gratefully acknowledge Ingrid Spurkland and Inger Helene Vandvik for their participation in recoding hospital records and for their crucial role in initiating and supporting the accomplishment of the study.

Open Access This article is distributed under the terms of the Creative Commons Attribution Noncommercial License which permits any noncommercial use, distribution, and reproduction in any medium, provided the original author(s) and source are credited.

\section{References}

Aasland, A., Flato, B., \& Vandvik, I. H. (1997). Psychosocial outcome in juvenile chronic arthritis: A nine-year follow-up. Clinical and Experimental Rheumatology, 15, 561-568.

Allen, D. A., Steinberg, M., Dunn, M., Fein, D., Feinstein, C., Waterhouse, L., et al. (2001). Autistic disorder versus other pervasive developmental disorders in young children: Same or different? European Child and Adolescent Psychiatry, 10, 67-78.

American Psychiatric Association. (2000). Diagnostic and statistical manual of mental disorders, text revised (DSM-IV-TR). Washington DC: American Psychiatric Association.

American Psychiatric Association. (2010). Retrieved at http://www. dsm5.org/ProposedRevisions/Pages/proposedrevision.aspx?rid= 94.

Baghdadli, A., Picot, M. C., Michelon, C., Bodet, J., Pernon, E., Burstezjn, C., et al. (2007). What happens to children with PDD when they grow up? Prospective follow-up of 219 children from preschool age to mid-childhood. Acta Psychiatrica Scandinavica, 115, 403-412.

Billstedt, E., Gillberg, C., \& Gillberg, C. (2005). Autism after adolescence: population-based 13-22 year follow-up study of 120 individuals with autism diagnosed in childhood. Journal of Autism and Developmental Disorders, 35, 351-360.

Bird, H. R., Canino, G., Rubio-Stipec, M., \& Ribera, J. C. (1987). Further measures of the psychometric properties of the children's global assessment scale. Archives of General Psychiatry, 44, 821-824.

Bird, H. R., Yager, T. J., Staghezza, B., Gould, M. S., Canino, G., \& Rubio-Stipec, M. (1990). Impairment in the epidemiological measurement of childhood psychopathology in the community. Journal of the American Academy of Child and Adolescent Psychiatry, 29, 796-803.

Bird, H. R., Andrews, H., Schwab-Stone, M., Goodman, S., Dulcan, M., Richters, J., et al. (1996). Global measures of impairment for epidemiologic and clinical use with children and adolescents. International Journal of Methods in Psychiatric Research, 6, 295-307.

Buitelaar, J. K., Van der Gaag, R., Klin, A., \& Volkmar, F. (1999). Exploring the boundaries of pervasive developmental disorder not otherwise specified: Analyses of data from the DSM-IV autistic disorder field trial. Journal of Autism and Developmental Disorders, 29, 33-43.

Cederlund, M., Hagberg, B., Billstedt, E., Gillberg, I. C., \& Gillberg, C. (2007). Asperger syndrome and autism: A comparative longitudinal follow-up study more than 5 years after original diagnosis. Journal of Autism and Developmental Disorders, 38(1), 72-85. 
DeMaso, D. R., Twente, A. W., Spratt, E. G., \& O’Brien, P. (1995). Impact of psychologic functioning, medical severity, and family functioning in pediatric heart transplantation. Journal of Heart and Lung Transplantion, 14, 1102-1108.

First, M. B., Pincus, H. A., Levine, J. B., Williams, J. B., Ustun, B., \& Peele, R. (2004). Clinical utility as a criterion for revising psychiatric diagnoses. American Journal of Psychiatry, 161, 946-954.

Flato, B., Aasland, A., Vandvik, I. H., \& Forre, O. (1997). Outcome and predictive factors in children with chronic idiopathic musculoskeletal pain. Clinical and Experimental Rheumatology, $15,569-577$.

Fombonne, E. (2005). Epidemiology of autistic disorder and other pervasive developmental disorders. Journal of Clinical Psychiatry, 66(Suppl 10), 3-8.

Gillberg, C., \& Steffenburg, S. (1987). Outcome and prognostic factors in infantile autism and similar conditions: a populationbased study of 46 cases followed through puberty. Journal of Autism and Developmental Disorders, 17, 273-287.

Gillberg, C., Billstedt, E., Sundh, V., \& Gillberg, I. C. (2010). Mortality in autism: a prospective longitudinal community-based study. Journal of Autism and Developmental Disorders, 40, 352-357.

Gold, J., Shera, D., \& Clarkson, B., Jr. (1993). Private psychiatric hospitalization of children: Predictors of length of stay. Journal of the American Academy of Child and Adolescent Psychiatry, $32,135-143$.

Grann, M., Langstrom, N., Tengstrom, A., \& Stalenheim, E. G. (1998). Reliability of file-based retrospective ratings of psychopathy with the PCL-R. Journal of Personality Assessment, $70,416-426$

Hofvander, B., Delorme, R., Chaste, P., Nyden, A., Wentz, E., Stahlberg, O., et al. (2009). Psychiatric and psychosocial problems in adults with normal-intelligence autism spectrum disorders. BMC Psychiatry, 9, 35.

Howlin, P. (1997). Prognosis in autism: do specialist treatments affect long-term outcome? European Child and Adolescent Psychiatry, $6,55-72$.

Howlin, P., Mawhood, L., \& Rutter, M. (2000). Autism and developmental receptive language disorder-a follow-up comparison in early adult life. II: Social, behavioural, and psychiatric outcomes. Journal of Child Psychology and Psychiatry, 41, $561-578$

Howlin, P., Goode, S., Hutton, J., \& Rutter, M. (2004). Adult outcome for children with autism. Journal of Child Psychology and Psychiatry and Allied Disciplines, 45(2), 212-229.

Kjelsberg, E., \& Dahl, A. A. (1998). High delinquency, disability and mortality-a register study of former adolescent psychiatric inpatients. Acta Psychiatrica Scandinavica, 98, 34-40.

Kobayashi, R., Murata, T., \& Yoshinaga, K. (1992). A follow-up study of 201 children with autism in Kyushu and Yamaguchi areas, Japan. Journal of Autism and Developmental Disorders, 22, 395-411.

Larsen, F. W. \& Mouridsen, S. E. (1997). The outcome in children with childhood autism and Asperger syndrome originally diagnosed as psychotic. A 30-year follow-up study of subjects hospitalized as children. European Child and Adolescent Psychiatry, 6(4), 181-190.

Lotter, V. (1974). Social adjustment and placement of autistic children in Middlesex: A follow-up study. Journal of Autism and Childhood Schizophrenia, 4, 11-32.

McKenzie, K., Scott, D. A., Waller, G. S., \& Campbell, M. (2011). Reliability of routinely collected hospital data for child maltreatment surveillance. BMC Public Health, 11, 8.
Mouridsen, S. E., Rich, B., Isager, T., \& Nedergaard, N. J. (2007). Pervasive developmental disorders and criminal behaviour: A case control study. International Journal of Offender Therapy and Comparative Criminology, 52(2), 196-205.

Mouridsen, S. E., Bronnum-Hansen, H., Rich, B., \& Isager, T. (2008). Mortality and causes of death in autism spectrum disorders: an update. Autism, 12, 403-414.

Piven, J., Harper, J., Palmer, P., \& Arndt, S. (1996). Course of behavioral change in autism: a retrospective study of high-IQ adolescents and adults. Journal of the American Academy of Child and Adolescent Psychiatry, 35, 523-529.

Seltzer, M. M., Shattuck, P., Abbeduto, L., \& Greenberg, J. S. (2004). Trajectory of development in adolescents and adults with autism. Mental Retardation and Developmental Disabilities Research Reviews, 10, 234-247.

Shaffer, D., Gould, M. S., Brasic, J., Ambrosini, P., Fisher, P., Bird, H., et al. (1983). A children's global assessment scale (CGAS). Archives of General Psychiatry, 40, 1228-1231.

Shavelle, R. M., Strauss, D. J., \& Pickett, J. (2001). Causes of death in autism. Journal of Autism and Developmental Disorders, 31, 569-576.

Siponmaa, L., Kristiansson, M., Jonson, C., Nyden, A., \& Gillberg, C. (2001). Juvenile and young adult mentally disordered offenders: the role of child neuropsychiatric disorders. Journal of American Academy of Psychiatry Law, 29, 420-426.

Skardhamar, T. (2010). Lovbruddskarrierer og levekår (criminal career and life conditions). Statistics Norway.

Sourander, A., Leijala, H., Lehtila, A., Kanerva, A., Helenius, H., \& Piha, J. (1996). Short-term child psychiatric inpatient treatment. Place of residence as one-year outcome measure. European Child and Adolescent Psychiatry, 5, 38-43.

StatBank Norway. (2005). Retrieved from http://www.statbank.ssb. no/statistikkbanken.

Szatmari, P. (2009). More than counting: milestones in child and adolescent psychiatric epidemiology. Journal of the American Academy of Child and Adolescent Psychiatry, 48, 353-355.

Szatmari, P., Merette, C., Bryson, S. E., Thivierge, J., Roy, M. A., Cayer, M., et al. (2002). Quantifying dimensions in autism: a factor-analytic study. Journal of the American Academy of Child and Adolescent Psychiatry, 41, 467-474.

Szatmari, P., Bryson, S. E., Boyle, M. H., Streiner, D. L., \& Duku, E. (2003). Predictors of outcome among high functioning children with autism and Asperger syndrome. Journal of Child Psychology and Psychiatry, 44, 520-528.

The Norwegian Labour and Welfare Administration. (2005). Retrieved from http://www.nav.no/805323065.cms.

Vandvik, I. H., Hoyeraal, H. M., \& Fagertun, H. (1989). Chronic family difficulties and stressful life events in recent onset juvenile arthritis. Journal of Rheumatology, 16, 1088-1092.

Volkmar, F. R., State, M., \& Klin, A. (2009). Autism and autism spectrum disorders: Diagnostic issues for the coming decade. Journal of Child Psychology and Psychiatry, 50, 108-115.

von Knorring, A. L., \& Hagglof, B. (1993). Autism in northern Sweden: A population based follow-up study: Psychopathology. European Child and Adolescent Psychiatry, 2(2), 91-97.

Walker, D. R., Thompson, A., Zwaigenbaum, L., Goldberg, J., Bryson, S. E., Mahoney, W. J., et al. (2004). Specifying PDDNOS: A comparison of PDD-NOS, Asperger syndrome, and autism. Journal of the American Academy of Child and Adolescent Psychiatry, 43, 172-180.

Winters, N. C., Collett, B. R., \& Myers, K. M. (2005). Ten-year review of rating scales, VII: Scales assessing functional impairment. Journal of the American Academy of Child and Adolescent Psychiatry, 44, 309-338. 